\title{
International Experiences in Assessing Vitamin A Status and Applying the Vitamin A-Labeled Isotope Dilution Method
}

${ }^{1}$ Nutritional Sciences, Department of Biological and Chemical Sciences, Universidad de Sonora, Hermosillo, Mexico; Research Center for Food and Development, Sonora, Mexico

${ }^{2}$ Tropical Diseases Research Centre, Ndola Central Hospital, Ndola, Zambia ${ }^{3}$ Laboratoire de Nutrition, Département de Biologie Animale, Faculté des Sciences et Techniques, Université Cheikh Anta Diop de Dakar (UCAD), Dakar, Senegal ${ }^{4}$ Center for Applied Health Technology and Clinical Epidemiology, National Institute of Health Research and Development (NIHRD) Ministry of Health, Bogor, Indonesia ${ }^{5}$ Centre for Food and Nutrition Research, IMPM (Institut de recherches medicales et d'etudes des plantes medicinales), Yaoundé, Cameroon ${ }^{6}$ Kintampo Health Research Centre, Kintampo, Ghana ${ }^{7}$ Sundar Serendipity Foundation, Chennai, India ${ }^{8}$ Department of Nutrition, School of Public Health, Nanjing Medical University, Nanjing, Jiangsu, PR China ${ }^{9}$ Institute of Nutrition, Mahidol University, Nakhon Pathom, Thailand ${ }^{10}$ Nutritional and Health-Related Environmental Studies Section, Division of Human Health, IAEA, Vienna, Austria

\begin{abstract}
Inadequate vitamin A (VA) nutrition continues to be a major problem worldwide, and many interventions being implemented to improve VA status in various populations need to be evaluated. The interpretation of results after an intervention depends greatly on the method selected to assess VA status. To evaluate the effect of an intervention on VA status, researchers in Cameroon, India, Indonesia, Mexico, Senegal and Zambia have used serum retinol as an indicator, and have not always found improvement in response to supplementation. One problem is that homeostatic control of serum retinol may mask positive effects of treatment in that changes in concentration are observed only when status is either moderately to severely depleted or excessive. Because VA is stored mainly in the liver, measurements of hepatic VA stores are the "gold standard" for assessing VA status. Dose response tests such as the relative dose response (RDR) and the modified relative dose response (MRDR), allow a qualitative assessment of VA liver stores. On the other hand, the use of the vitamin A-labeled isotope dilution (VALID) technique, (using ${ }^{13} \mathrm{C}$ or ${ }^{2} \mathrm{H}$-labeled retinyl acetate) serves as an indirect method to quantitatively estimate total body and liver VA stores. Countries including Cameroon, China, Ghana, Mexico, Thailand and Zambia are now applying the VALID method to sensitively assess changes in VA status during interventions, or to estimate a population's dietary requirement for VA. Transition to the use of more sensitive biochemical
\end{abstract}


indicators of VA status such as the VALID technique is needed to effectively assess interventions in populations where mild to moderate VA deficiency is more prevalent than severe deficiency.

Key words: Vitamin A status, children, lactating women, stable isotope dilution, labeled retinol, Cameroon, China, Ghana, India, Indonesia, Mexico, Senegal, Thailand, Zambia

\section{Introduction}

Vitamin A deficiency (VAD) continues to be a major nutritional problem in the developing world. Clinical manifestations of VAD include anemia, reduced immune function, xerophthalmia, and ultimately blindness and death $[1,2]$. Even a marginal-subclinical deficiency of VA can adversely affect health [3]. According to estimates by the World Health Organization (WHO), about 190 million children $<5$ years and 19.1 million pregnant women have a low serum retinol (SR) concentration $(<0.7 \mu \mathrm{mol} / \mathrm{L})$ [1]. To reduce the burden of VAD in developing countries, different strategies have been implemented by governmental and non-governmental organizations to improve VA status. Programs include supplementation, food fortification, biofortification and education, with particular focus on children $<5 \mathrm{y}$ and pregnant and lactating women. In this manuscript, we will discuss international experience with assessment of interventions to improve VA status in Cameroon, China, Ghana, India, Indonesia, Mexico, Senegal, Thailand and Zambia, based on experiences related by participants in the International Atomic Energy Agency meeting "Applying Vitamin A Isotope Dilution Techniques to Benefit Human Nutrition" (St. John's Research
Institute, Bangalore, India; 7-9 October, 2013). This meeting emphasized the transition toward the use of vitamin A-labeled isotope dilution (VALID) methods to measure VA total body stores (TBS).

The need for an accurate assessment of the efficacy and effectiveness of interventions to improve VA status in the above-listed countries, especially in the most vulnerable groups, including preschool-age children and pregnant and lactating women, is emphasized by data (Table I) which rate the public health significance of VAD using the prevalence of low SR concentration $(<0.7 \mu \mathrm{mol} / \mathrm{L})$ as an indicator.

These data clearly indicate that VAD is a significant public health problem in children under 5 years old as well as pregnant and lactating women in these countries. As discussed below, interventions have been designed to reduce VAD in each of these countries, but the outcome has not always been satisfactory. To some extent, this finding may be attributable to the biochemical indicator chosen to assess the effect of the intervention on VA status. The strengths and limitations of different indicators to assess VA status are briefly summarized in Table II, and will be further considered with country-specific experiences dealing with VA interventions, assessments, and strategies to improve VA status in women and children.

Table I: Prevalence of VAD (serum retinol $<0.7 \mu \mathrm{mol} / \mathrm{L}$ ) and public health significance according to the World Health Organization

\begin{tabular}{|c|c|c|c|c|}
\hline & \multicolumn{2}{|c|}{ Children $<5$ y } & \multicolumn{2}{|c|}{ Pregnant women } \\
\hline & Prevalence & Public Health Problem & Prevalence & Public Health Problem \\
\hline Cameroon & 38.8 & Severe & 17.9 & Moderate \\
\hline China & 9.3 & Mild & 22.8 & Severe \\
\hline Ghana & 75.8 & Severe & 18.1 & Moderate \\
\hline India & 62 & Severe & 16.4 & Moderate \\
\hline Indonesia & 19.6 & Moderate & 17.1 & Moderate \\
\hline Mexico & 26.8 & Severe & 1.9 & No \\
\hline Senegal & 37 & Severe & 19.4 & Moderate \\
\hline Thailand & 15.7 & Moderate & 1.7 & No \\
\hline Zambia & 54.1 & Severe & 14 & Moderate \\
\hline
\end{tabular}

Notes: Adapted from [1]; assessment data were collected from 1995 to 2005. 
Table II: Strengths and limitations of different biochemical indicators to assess VA status.

\begin{tabular}{|c|c|c|c|}
\hline $\begin{array}{l}\text { Biochemical } \\
\text { Indicator of VA } \\
\text { status }\end{array}$ & $\begin{array}{l}\text { Range of aso- } \\
\text { ciation with liver } \\
\text { VA stores1 }\end{array}$ & Response to Interventions & Limitations \\
\hline Serum retinol & $\begin{array}{l}\text { Deficient to } \\
\text { moderate }\end{array}$ & $\begin{array}{l}\text { Most commonly used indicator in } \\
\text { field studies. } \\
\text { Not optimal to assess interventions } \\
\text { with marginal VA status or } \\
\text { inflammation. }\end{array}$ & $\begin{array}{l}\text { Under homeostatic control. } \\
\text { Negatively affected by subclinical } \\
\text { infection, inflammation, inadequate } \\
\text { intakes of protein, energy or zinc, } \\
\text { which are required for retinol bin- } \\
\text { ding protein synthesis. }\end{array}$ \\
\hline Breastmilk retinol & $\begin{array}{l}\text { Deficient to } \\
\text { moderate }\end{array}$ & $\begin{array}{l}\text { Easy to obtain. } \\
\text { Sensitive with interventions for } \\
\text { VAD women and infants. } \\
\text { Not affected by inflammation. }\end{array}$ & $\begin{array}{l}\text { Milk composition depends on stage } \\
\text { of lactation (i.e. colostrum, transiti- } \\
\text { onal milk and mature milk). } \\
\text { Results may differ between casual } \\
\text { vs. full sampling techniques. } \\
\text { May reflect recent dietary VA } \\
\text { intake and not VA status. } \\
\text { Analysis needs saponification of re- } \\
\text { tinyl esters and thus special analytic } \\
\text { considerations. }\end{array}$ \\
\hline $\begin{array}{l}\text { Dose response } \\
\text { tests (RDR and } \\
\text { MRDR) }\end{array}$ & $\begin{array}{l}\text { Deficient to } \\
\text { adequate }\end{array}$ & $\begin{array}{l}\text { Sensitive with interventions for } \\
\text { severe to marginal VAD. } \\
\text { Easy to implement in field studies. } \\
\text { Provides a qualitative estimate of } \\
\text { liver stores. } \\
\text { RDR has been validated against } \\
\text { liver stores. } \\
\text { MRDR strongly correlates with } \\
\text { RDR. }\end{array}$ & $\begin{array}{l}\text { RDR requires two blood collections } \\
\text { on the same day. } \\
\text { MRDR requires only one blood } \\
\text { draw but uses } 3,4 \text {-didehydroretinyl } \\
\text { acetate (not commercially available } \\
\text { and difficult to synthesize). } \\
\text { Effective dose may depend on the } \\
\text { subject's nutritional status. } \\
\text { Parasite infections (e.g., ascariasis } \\
\text { or giardiasis) may complicate inter- } \\
\text { pretation of results. }\end{array}$ \\
\hline VALID technique & $\begin{array}{l}\text { Deficient to } \\
\text { sub-toxic }\end{array}$ & $\begin{array}{l}\text { ensitive with interventions across } \\
\text { a full range of VA status. } \\
2 \mathrm{H} \text { or } 13 \mathrm{C} \text { labeled retinol can be } \\
\text { used as markers. } \\
\text { Can be implemented in field studies. } \\
\text { Provides a quantitative estimate } \\
\text { of total body VA pool size and } \\
\text { VA liver stores. } \\
\text { Enables estimation of VA dietary } \\
\text { requirement. }\end{array}$ & $\begin{array}{l}\text { High-cost equipment to analyze the } \\
\text { isotopic enrichment ratio. } \\
\text { Validation for the use of VALID } \\
\text { technique in pregnant and lactating } \\
\text { women is needed. } \\
\text { Lack of Information on the effects } \\
\text { of inflammation and malnutrition } \\
\text { and/or toxicity, in the interpretation } \\
\text { of the VALID technique. }\end{array}$ \\
\hline Liver sample & $\begin{array}{l}\text { Deficient to } \\
\text { toxic }\end{array}$ & $\begin{array}{l}\text { Gold standard to assess VA status. } \\
\text { Sensitive responder to assess } \\
\text { interventions. }\end{array}$ & $\begin{array}{l}\text { Not feasible for field work } \\
\text { VA is distributed in different areas } \\
\text { of the liver and to know the concen- } \\
\text { tration only one sample may not be } \\
\text { representative }\end{array}$ \\
\hline
\end{tabular}

Notes: Table constructed from references: [4-10]. ${ }^{1}$ Adapted from [4].

\section{Cameroon}

In 1980, a study based on SR and carotenoid concentrations showed that the VA requirement of Cameroonians was being met [11]. Nevertheless, further studies showed that clinical signs of VAD were evident in the population and represented a moderate public health problem according to WHO criteria $[12,13]$. The National Survey on Vitamin A Deficiency and
Anemia showed that almost $40 \%$ of children $<5$ years old were VA deficient based on low SR concentration [14]. This represents a severe public health problem, although it may be an overestimate because inflammation, which is known to lower circulating retinol concentration, was not assessed [14].

In response, in 2002, the government of Cameroon launched a bi-annual VA supplementation program (200,000 IU; $60 \mathrm{mg}$ ) for children aged 6-59 months to 
improve VA status. Unfortunately, there was no clinical or subclinical evaluation of the program. However, in 2009 a national survey was done in preparation for a large-scale food fortification program (mandatory fortification of oil) and indicators of VA status and inflammation were assessed before the fortification was begun. Adjusted results showed that $35 \%$ of children under 5 years had VAD, which thus remains a severe public health problem [15]. These results suggest that the efforts through the national supplementation program have not been sufficient to improve VA status in the population's children. However, a limitation to this conclusion is that the assessment of VA status was based on the determination of SR concentration, which is not an optimal indicator to assess the response to an intervention [4].

Because SR is homeostatically controlled and VA assessment is difficult in settings where infectious diseases are common [4], a more suitable biomarker was sought. Therefore, Cameroon is establishing the VALID technique for the determination of VA status at the Institute of Medical Research and Medicinal Plants Studies. A pilot study is currently being conducted to assess the effectiveness of the VA supplementation program for children $<5 y$ using the VALID technique to quantitatively assess the impact of supplementation on the VA TBS of Cameroonian preschool age children.

\section{China}

The 2002 National Survey on Nutrition and Health Status of the Chinese Population showed that the prevalence of VAD (SR $<0.7 \mu \mathrm{mol} / \mathrm{L})$ among children $3-12$ years old was $9.3 \%$ (3.0\% and $11.2 \%$ in the urban and rural areas respectively); the prevalence of marginal VAD (SR 0.7-1.05 $\mathrm{mol} / \mathrm{L}$ ) was $45.1 \%$ (29.0\% and $49.6 \%$ for the urban and rural areas respectively) [16, 17]. Based on these assessments using $\mathrm{SR}$, children in rural communities were at greater risk of VAD than in urban communities but overall, VAD represented a mild public health problem for the children of China (Table I).

In China, the VALID technique has been used in several reports of VA status assessment. These included an intervention study in preschool children to evaluate the use of green and yellow vegetables to maintain VA TBS [18]. A methodological report showed that serum deuterium enrichment in school children 3 days after the isotope dose correlated well with enrichment after the usual 21 day equilibration time, which supports a potential simplification of the
VALID technique in field settings [19]. The VALID technique has also been used to determine the conversion factor of pure $\beta$-carotene in oil to retinol in Chinese adults (conversion of $9.1: 1$ by weight) [20, $21]$, and to assess the conversion of $\beta$-carotene in oil, in golden rice and in spinach (conversion of 2.3, 2.0 and 7.5 to 1 respectively), in Chinese schoolchildren [22]. More recently, the VALID technique has been employed to assess the dietary requirements of VA for healthy children and adults [23]. Wang et al. [24] determined the amount of dietary $\mathrm{VA}$ required to maintain constant VA TBS in 104 Chinese adults (52 men and 52 women); the results suggested average requirements of $472 \mu \mathrm{g}$ / day for Chinese women and $561 \mu \mathrm{g} /$ day for men. Another study by Zeng et al. [25] assessed the VA intakes of well-nourished Chinese children associated with liver retinol stores between $0.07-1.05 \mu \mathrm{mol} / \mathrm{g}$ as determined by the VALID technique; results suggested that VA intakes of $450 \mu \mathrm{g}$ / day for children $4-6$ years and $550 \mu \mathrm{g}$ / day for children 7-9 years were adequate to maintain these desired liver stores. These last two studies in China, using the VALID technique to assess the VA status and to estimate the VA requirements of different population groups, are consistent with similar applications in Bangladesh and the United States [26, 27].

\section{Ghana}

In 2012, Ghana's government invested over $20 \%$ of its budget on education, primary health care, povertyfocused agriculture, rural water, feeder roads and rural electrification [28]. Many basic needs are unfulfilled in this country; nonetheless, efforts to improve Ghanaians' health are being supported by international researchers and NGO's.

As shown in Table I, Ghana is a country in which VAD is a severe public health problem [1]. One of the strategies used to reduce child morbidity and mortality is VA supplementation, which has been provided twice a year since 1997 during national immunization campaigns. According to the Ghana Demographic and Health Survey (2008), more than half (56\%) of children age 6-59 months were given a VA supplement in the six months prior to the survey, and $81 \%$ of children age $6-35$ months ate fruits and vegetables rich in VA within 24 hours prior to the survey [29], unfortunately VA status was not assessed biochemically, thus no prevalence on low serum retinol concentration is available from that survey. Ghana, as well as many 
other developing countries, relies on carotenoids as a source of VA. Takyi [30], in a 1999 double blind controlled study in preschool children from northern Ghana, showed that intake of dark green leafy vegetables with added fat significantly increased the proportion of children with adequate VA status from 28.2 to $48.2 \%$. Although an important percentage of participant children reached the cut-off for normality, mean SR concentration did not significantly change after feeding, confirming that SR is not especially sensitive to assess interventions.

Results are not yet available for a study from the Kintampo Health Research Centre to assess the effect of fortification of home based complementary foods with or without VA on VA stores using the VALID technique among children in Ghana. As with all of the international projects being mentioned, the collected samples were transported for mass spectroscopy analysis in the United States. Improving the user-friendliness of the VALID techniques in the field, by facilitating sample collection and transfer, or the local analyses of samples, is desirable for further application of the VALID method in Ghana and other countries that need more information on the VA status of the population to improve and target programs to fight VAD.

\section{India}

India has one of the highest rates of VAD in the world. Each year, VAD is associated with the deaths of 330,000 children in India [31]. Therefore, in 1970 the government of India launched the National Prophylaxis Programme against Nutritional Blindness due to VAD, which provides a high-dose VA supplement for children 9-59 months old [32]. Although VA status has improved in the past few decades, results of the Micronutrient Deficiencies Survey conducted in 2002-2003 by the National Nutrition Monitoring Bureau, indicated that $62 \%$ of preschoolers in India were VA deficient, having SR concentrations lower than $0.7 \mu \mathrm{mol} / \mathrm{L}[33,34]$. The same study showed that VA supplementation coverage was low among children $(30 \%)$, and this could in part explain why sub-clinical VAD is still highly prevalent in Indian preschoolers.

Given that supplementation alone has not been effective in eradicating VAD as a public health problem in India, additional interventions have been investigated for complementing government strategies to improve VA status, primarily using SR for evaluation. A study by Basu et al. [35] assessed the effect of VA megadose supplementation $(209 \mu \mathrm{mol})$ to mothers soon after delivery and results showed that breast milk retinol significantly increased from 3.85 to $12.08 \mu \mathrm{mol} / \mathrm{L}$ and this was maintained for up to four months; this also increased the SR concentrations of the breastfed babies for up to five months.

Additional strategies to reduce VAD among Indian children and adolescents have commonly involved multiple micronutrient supplementation. In a study without a control treatment group, micronutrientfortified biscuits containing $600 \mu \mathrm{g}$ VA consumed on work days for $8 \mathrm{wk}$ reduced the prevalence of low SR in adolescents [36]. In a placebo-controlled multinutrient supplement study that included $375 \mu \mathrm{g}$ VA administered for 8 months to dewormed 6-10 year old school children with mean baseline SR of $1.03-1.10 \mu \mathrm{mol} / \mathrm{L}$, the prevalence of low SR significantly decreased in both supplemented and control groups. In the same study, SR concentrations increased from baseline only in the supplemented group, but final SR concentrations did not significantly differ from the control group [37]. In a cluster randomized, controlled study by Varma et al. [38], there were unfortunate baseline differences between groups in SR, but not VAD prevalence, and no change was observed in either SR or VAD prevalence after an intervention with iron and VA (500 ug) premix. In a randomized controlled trial of children aged 5-18y with mean SR close to $0.7 \mu \mathrm{mol} / \mathrm{L}$, a micronutrient fortified salt including $\mathrm{VA}$ reduced the prevalence of VAD in children 5-18 years from $57 \%$ to $16 \%$, based on $\mathrm{SR}<0.7 \mu \mathrm{mol} / \mathrm{L}$ [39]. Similar beneficial results were obtained in a subsequent study by the same group, in which school children with mean SR close to $0.7 \mu \mathrm{mol} / \mathrm{L}$ had improved $\mathrm{SR}$ and lower prevalence of VAD from consumption of a micronutrient fortified salt including vitamin A, in comparison to a group receiving nutrition education only or an untreated control group [40].

The SR concentration was sensitive as a biochemical indicator in some, but not all of these studies, and inconsistently provided evidence of a reduction in the prevalence of VAD with interventions. When moderate to severe VAD is present in the population at baseline, it is possible to observe a significant increase in SR concentration. However, SR results are not consistently sensitive, and do not indicate whether VA status is marginal, adequate or perhaps excessive after long-term interventions. For instance, the fortified salt studies $[39,40]$ provided approximately $100 \%$ of the recommended allowance of VA for these children from fortified salt alone; although such levels of fortification benefited those with VAD, $\mathrm{SR}$ concentrations do not serve as a reliable indicator 
of possible excessive VA status when such doses are provided to those with adequate VA status. Although $\mathrm{SR}$ results continue to indicate sub-clinical VAD in India (Table I), the universal approach of megadose VA supplementation has been questioned [41], with reference to substantial decreases in clinical VAD as well as possible difficulties interpreting low SR, which can also result from infectious inflammation or from deficiencies of other nutrients such as protein, iron, or zinc involved in metabolism and transport of the vitamin (Table II).

\section{Indonesia}

The frequency of clinical signs of VAD has decreased in Indonesia. However based on SR concentration, VAD remains a moderate public health problem for children under 5 years and among pregnant women [1].

Since 1975, efforts have been made to reduce VAD in children, infants and post-partum women through high-dose supplementation twice a year in children under 5 years, reaching a coverage of about $86 \%$ of the targeted population [42]. Supplements of VA are also administered to women for two days immediately postpartum. In combination with these high-dose VA supplementation programs, in 2012 the government released the Indonesia National Standard for fortification of cooking oil, which is not mandatory for industries.

The assessment of VA status in Indonesia has included the use of different methods and their provisional cutoff points, such as SR $(<0.7 \mu \mathrm{mol} / \mathrm{L})$, RDR ( $\geq 20 \%)$, MRDR ( $\geq 0.06$ ratio) and conjunctival impression cytology (abnormality in one eye). Tanumihardjo et al. [43] compared VA assessment methods in Indonesian preschool-age children from two different villages with no clinical eye signs of VAD. In the study, there was a good agreement between abnormal conjunctival impression cytology and MRDR (51\% and $48 \%$, respectively), but interpretation of RDR results was difficult because it provided normal results even when SR was severely low $(<0.35 \mu \mathrm{mol} / \mathrm{L})$. In a second study that used a higher dose of retinol (3.5, rather than $1.57 \mu \mathrm{mol})$ for the RDR test, good agreement was obtained between RDR and MRDR results ( $11 \%$ and $12 \%$, respectively). These indicators gave concordant group results but did not necessarily identify the same individuals at risk [43].

A different study assessed the VA status of lactating $(n=64)$ and non-lactating $(n=14)$ non-pregnant Indonesian women, using the MRDR test; results $5 \mathrm{~h}$ after the 3,4-didehydroretinyl acetate was administered showed that $70 \%$ of lactating women and $7 \%$ of non-lactating women had inadequate VA stores (MRDR $\geq 0.06$ ) and only $7 \%$ of the variability could be attributed to differences in body weight [44].

In 2009, Rosmalina et al. [45] reported the change in VA status of breastfeeding mothers, with two interventions (i.e., postpartum VA supplementation, or use of VA-fortified cooking oil), in a 2 X2 factorial design. Mothers who received the fortified oil consumed about $575 \mu \mathrm{g} \mathrm{VA} /$ day (i.e., $23 \mathrm{~g}$ of fortified cooking oil/ day) for $80 \mathrm{~d}$. The two interventions, separately or combined, significantly prevented a reduction in SR concentration experienced by the group that did not receive either intervention. VA-liver reserves in this study were evaluated using the MRDR, a qualitative indicator of low liver VA stores [46], and did not further differentiate significantly between the treatments.

\section{Mexico}

VAD in Mexico is a severe subclinical public health problem, as assessed by SR concentration [1]. Data from the National Nutrition Survey in 1999, showed that moderate and severe VAD was present in $27 \%$ of children $0-6$ years old and $2 \%$ of children $0-4$ years old [47]. Efforts to reduce the burden of VAD include the administration of VA supplements to children 6-59 months $(60 \mathrm{mg})$ during national health campaigns since 1993. Although data are not available on the VA supplementation coverage rate in Mexico, it is estimated that $50-79 \%$ of the population receives two doses annually [42]. Robles et al. [48] assessed the effect of supplementation on the VA status (as SR) of Mexican children, and showed that supplementation provided an immediate improvement in VA status but its effectiveness was of limited duration. In this population, VAD frequently coexists with parasite infections such as Giardia lamblia, Entamoeba histolytica and Ascaris lumbricoides, which occur mainly through contaminated food or water. In a study of Mexican schoolchildren infected with Giardia lamblia, treatment of the parasitic infection improved their VA liver reserves (assessed by MRDR), but not their SR, possibly because most of the children did not have clearly inadequate liver VA stores (MRDR $>0.06)$ [49].

Another approach used to reduce VAD in Mexico is the distribution of VA-fortified milk for sectors of the population with low socioeconomic status or limited access to food. VA-fortified milk is included 
in the national school breakfast program, which has been shown to improve iron and zinc but not VA status [50]. In addition, a Mexican food aid program (Liconsa fortified milk, produced by a company subsidized by the Federal government) has been in effect since 2001 for high-risk sectors of the population. This fortified milk program has been statistically associated with a decrease in the prevalence of anemia in Mexican children [51], and a dietary analysis of preschoolers' VA intake showed that half of the daily recommended intake of VA comes from such industrial fortification [52]. Recently, a randomized controlled clinical trial assessed the effectiveness of the daily intake of $250 \mathrm{~mL}$ of VA-fortified Liconsa milk (196 retinol equivalents / day) for 3 months in 24 preschool-age children with marginal VAD (SR $>0.35$ and $<1.05 \mu \mathrm{mol} / \mathrm{L})$, using the VALID technique [53] before and after the intervention [54]. The VA-fortified milk increased SR, TBS and liver VA stores by a difference of $0.35 \mu \mathrm{mol} / \mathrm{L}, 0.05 \mathrm{mmol}$ and $0.08 \mu \mathrm{mol} / \mathrm{g}$ of liver, respectively between the intervention and control groups, $P<0.05$ [54]. However, the SR data were difficult to interpret, as mean SR did not change in the treatment group, but decreased in the control group (data not shown). Use of the VALID technique enabled quantitative assessment of the change in VA stores, and indicated that liver VA stores were within a range considered adequate but not excessive ( 0.1 to $1.0 \mu \mathrm{mol} / \mathrm{g}$ ) [4], even in the control group, whose stores did not change from baseline. This provides meaningful data for monitoring the intervention.

\section{Senegal}

In Senegal deficiencies of micronutrients such as iron, iodine and VA are widespread and have physiological and economic consequences. In order to ameliorate VAD and reduce childhood mortality, the Senegalese government has focused on bi-annual VA supplementation for children 6-59 months. Additionally, breastfeeding promotion, production and consumption of micronutrient rich foods and more recently a VA oil fortification program, are available as complementary strategies.

The VA status of vulnerable groups has improved in recent years. The estimated prevalence of VAD (based on SR $<0.7 \mu \mathrm{mol} / \mathrm{L}$ ) was $37 \%$ in young children and $19.4 \%$ in pregnant women, from a 2005 survey (Table I) [1]. Before the food fortification program was launched, another national representative baseline survey was conducted in 2010, using
$\mathrm{SR}$ as the biochemical indicator. This national study showed that only $1.9 \%$ of childbearing age women had moderate VAD $(<0.7 \mu \mathrm{mol} / \mathrm{L})$ and $14.2 \%$ had marginal VA nutrition $(0.7-1.05 \mu \mathrm{mol} / \mathrm{L})$ [55]. Among children aged $12-59$ months, $17.2 \%$ were VAD (0.35-0.7 $\mathrm{mol} / \mathrm{L})$ [56]. Therefore according to the WHO definition, VAD was a public health problem among children aged 12-59 months, but not among women [1]. Further studies need to be performed, using more sensitive indicators such as the MRDR test or VALID technique, given that VA liver stores or TBS were not measured.

In a sample of mother/infant pairs at 6 mo postpartum $(n=34)$, SR detected $8.8 \%$ VAD among mothers and $15 \%$ among infants [57]. However, a qualitative assessment of liver stores using the MRDR test showed that $73.5 \%$ of the infants had low liver stores. Liver stores were significantly higher in infants whose mothers were VA supplemented post-partum, compared with infants of non-supplemented mothers $(\mathrm{P}=0.009)$, although neither maternal plasma retinol nor milk retinol concentrations differed between the two groups of mothers. In lactating women, breast milk retinol concentration can serve as a useful indicator of VA status [12] and additionally provides information on the infants' VA intake; in this study VA intake from breast milk was adequate compared to current recommendations $(\sim 375 \mu \mathrm{g} / \mathrm{d})$; nevertheless, MRDR $\geq 0.06$, suggestive of low liver concentrations, was observed in $53.8 \%$ and $95 \%$ of infants from the supplemented and non-supplemented mothers, respectively [57]. Quantitative assessments of VA stores in Senegalese children are desirable to help evaluate the impact of interventions such as the national VA fortification of cooking oil and the national program of VA supplementation.

\section{Thailand}

Thailand is a transition country, with a decreasing prevalence of undernutrition and a rapidly rising prevalence of overnutrition. Although significant progress has been made over the past two decades in terms of policy and programmatic development, VAD is still a problem of public health concern amongst sectors of the Thai population [1].

While micronutrient malnutrition (zinc, iron, iodine and VA) still exists in a mild to moderate degree in Thailand, there are no national high-dose VA supplementation or food fortification programs, except for universal salt iodization. Thailand's strategy is to tar- 
get interventions, such as high-dose VA supplementation and food fortification, to those who need it the most and thus improve the health of the population while more efficiently using economic resources. High dose VA capsules have been provided when clinical signs of VAD were detected. When clinical signs disappeared, the supplementation program was stopped and dietary intake of VA foods was promoted [58].

In Thailand, as in many other Asian countries, multiple micronutrient deficiencies commonly coexist and rice, one of the leading staple foods, contains little $\mathrm{Fe}, \mathrm{Zn}$, or VA. Therefore, rice was evaluated as a potential food for fortification to reduce deficiencies of these micronutrients in the Thai population. A randomized controlled trial was conducted to evaluate the impact on VA status of triple-fortified rice $(9 \mathrm{mg} \mathrm{Zn}, 10 \mathrm{mg} F e$, and $890 \mu \mathrm{g}$ VA as retinyl palmitate in $140 \mathrm{~g}$ cooked rice) consumed 5 days per week for 2 months by school-age children from Satun (south Thailand) whose SR was $>0.7 \mu \mathrm{mol} / \mathrm{L}$ ) [59]. Eating fortified rice did not affect SR concentration, but significantly increased the children's liver VA stores, using the VALID method, without any change in the control group. The prevalence of VAD (based on liver VA of $<0.07 \mu \mathrm{mol} / \mathrm{g}$ ) was reduced by about half in the treated children, in contrast to the controls, a difference which was not detectable with SR. Future research plans in Thailand include the use of the VALID technique to assess the efficacy of fortified rice to improve breast milk retinol and VA liver reserves in lactating women.

\section{Zambia}

VAD is highly prevalent in Africa especially SubSaharan Africa, with the underlying cause being diets that are chronically insufficient in VA [1]. Additionally, VAD coexists with a high prevalence of infection, which may impair VA status [60] or at least the evaluation of VA status with SR [61-63].

In Zambia, children between 6 months and 5 years currently receive high-dose VA supplements $(100,000$ IU [30 mg] from 6-12 months; 200,000 IU [60 mg] from 12-60 months), once every six months with a coverage rate of $96 \%$ [42]. Additionally, there is a national program that provides VA-fortified sugar to the population. A national survey conducted in 2003 indicated that about $54 \%$ of children under 5 years of age had low SR $(\leq 0.7 \mu \mathrm{mol} / \mathrm{L}) 30$ days after high-dose VA supplements were distributed [64]. This unexpected finding was more common with inflammation (elevated C-reactive protein) or the presence of malaria parasites in the blood. Against this background, two different studies are being conducted to assess the impact of an intervention on VA stores:

A double blind, placebo controlled efficacy study is using the VALID technique to assess whether the administration of a high-dose VA supplement has a sustained (30-d after administration) effect on VA TBS in children 3-5 years of age. Additional to VAstores, weekly morbidity and dietary (food frequency) data will be evaluated, to examine relationships between morbidity and usual intake of VA-containing foods with the observed changes in VA status.

An efficacy study will determine changes in VA TBS in response to the consumption of a biofortified crop (orange maize) by Zambian children.

Recently a study by Bresnahan et al. [65] in Zambian children 3 to 5 years of age assessed the effect of inflammation on indicators of VA status during a randomized controlled feeding trial. The results showed that SR concentration significantly decreased 20-30\% during early convalescence (elevated C-reactive protein) $(P<0.05)$. Additionally, the MRDR test was not affected by the acute phase response (elevations in C-reactive protein and/or $\alpha_{1}$-acid glycoprotein). However, the MRDR values increased $(16 \%, P<0.05)$ during the 3 mo study, indicating that liver stores were being decreased, possibly reflecting change between administrations of the semiannual VA supplementation program.

\section{Conclusions}

This report summarizes different approaches by several countries to ameliorate VAD, particularly in children under 5 years old and in pregnant and lactating women. Unfortunately, these strategies are not always accompanied by an assessment of the intervention on the VA status of beneficiaries, and it is most common to use SR concentration as the biochemical indicator, which due to homeostatic control is not very responsive to interventions, especially when VAD is mild. Furthermore, in most developing countries infections are common, which may reduce SR, possibly independent of VA status. Thus, the assessment of VA status should be accompanied by measurements of inflammation markers such as C-reactive protein and plasma $\alpha 1$-acid glycoprotein.

Currently, the countries discussed (Cameroon, China, Ghana, India, Indonesia, Mexico, Senegal, Thailand and Zambia), are looking for better ways 
to address VAD, and are applying more sensitive techniques that enable estimation of VA-liver stores. The VALID technique is the method of choice to assess VA status, response to interventions and the dietary adequacy of VA intake for different population groups. This technique is highly sensitive, but the equipment needed to perform the isotope analysis such as gas chromatography/electron capture negative chemical ionization-mass spectrometry [66], gas chromatography/combustion/isotope ratio mass spectrometry [67], and more recently liquid chromatography-tandem mass spectrometry [68], are expensive. Additionally, although the improved methodological sensitivity allows the use of smaller stable isotope doses, labeled retinyl acetate (i.e. ${ }^{2} \mathrm{H}$ or ${ }^{13} \mathrm{C}$ ) is not inexpensive. These expenses as well as a relatively high involvement required of the study subjects, including multiple blood samples scheduled for several days limits the use of the VALID technique to assess VA status in large epidemiological studies. However, the VALID technique can be strategically used as the most sensitive way to answer questions about VA status, the impact of VA interventions, and the VA requirements of vulnerable population groups.

Further research is needed to continue to develop available equations to estimate liver VA stores and establish recommendations to distinguish between mild deficiency, adequate intakes, and risk of excessive intakes. This is especially true in settings where mild VAD is more prevalent than moderate or severe deficiency, and infectious diseases are endemic (inflammation). Further work is needed for interpreting the results of the VALID technique with different ages and physiological conditions such as pregnancy, lactation, or obesity.

\section{Acknowledgements}

Thank you to Joanne B. Green and Michael H. Green, for their valuable work in the editing of the manuscript.

\section{Abbreviations}

MRDR: modified relative dose response

RDR: relative dose response

SR: $\quad$ serum retinol

TBS: $\quad$ total body stores

VA: Vitamin A

VAD: Vitamin A deficiency

VALID: Vitamin A labeled isotope dilution

\section{References}

1. WHO (2009): Global prevalence of vitamin A deficiency in populations at risk 1995-2005. WHO global database on vitamin A deficiency. Geneva, World Health Organization.

2. D'Ambrosio, D., Clugston, R., Blaner, W. (2011) Vitamin A metabolism: an update. Nutrients 3, $63-103$.

3. Sommer, A. (1995). Vitamin A deficiency and its consequences a field guide to detection and control, pp 6, World Health Organization, Geneva.

4. Tanumihardjo, S.A. (2011). Vitamin A: biomarkers of nutrition for development. Am. J. Clin. Nutr. 94, $658 \mathrm{~S}-65 \mathrm{~S}$

5. Tanumihardjo, S., Nestel, P., Furr, H., Green, M. H., Haskell, M., Mokhtar, N., Ribaya-Mercado, J., Wasantwisut, E. (2004). Appropriate uses of vitamin A tracer (stable isotope) methodology. Vitamin A tracer task force. ILSI Human Nutrition Institute, Washington D.C.

6. Tanumihardjo, S. A. (2012). Biomarkers of vitamin A status: what do they mean? In: World Health Organization. Report: Priorities in the assessment of vitamin A and iron status in populations, Panama City, Panama, 15-17 September 2010. Geneva, World Health Organization.

7. Furr, H., Green, M. H., Haskell, M., Mokhtar, N., Nestel, P., Newton, S., Ribaya-Mercado, J., Tang, G., Tanumihardjo, S., Wasantwisut, E. (2004). Stable isotope dilution techniques for assessing vitamin A status and bioefficacy of provitamin A carotenoids in humans. Pub. Health. Nutr. 8, 596-607.

8. Smith, J.E., Brown, E.D., Smith, J.C. Jr. (1974). The effect of zinc deficiency on the metabolism of retinolbinding protein in the rat. J. Lab. Clin. Med. 84, $692-7$.

9. Stoltzfus, R.J., Underwood, B.A. (1995). Breast-milk vitamin $\mathrm{A}$ as an indicator of the vitamin A status of women and infants. Bull. World Health. Org. 73, $703-11$.

10. Dancheck, B., Nussenblat, V., Ricks, M.O., Kumwenda, N., Neville, M.C., Moncrief, D.T., Taha, T.E., Semba, R.D. (2005). Breast milk retinol concentrations are not associated with systemic inflammation among breast-feeding women in Malawi. J. Nutr. 135, 223-6.

11. Le Francois, P., Chevassus-Agnes, S., Benefice, E., Dyck, J. L., Maire, B., Parent, G., Seymat, G., Ndiaye, A. M. (1980). Vitamin A status of populations in three 
West African countries. Int. J. Vitam. Nutr. Res. 50, $352-63$.

12. World Health Organization. Indicators for assessing vitamin Adeficiencyand theirapplicationinmonitoring and evaluating intervention programmes. Geneva, World Health Organization, 1996 (WHO/NUT/96.10) (http://whqlibdoc.who.int/hq/1996/WHO_NUT_ 96.10.pdf).

13. Atina, E., Wilson, R., et al. (1992) Prevalence of Xerophthalmia and Risk of Vitamin A Deficiency among children in the extreme north of Cameroon. 1992. In: WHO MDIS working paper \#2 WHO/NUT/95.3.

14. Ministère de la Santè Publique. (2001). Cameroun enquete nationale sur la carence en vitamine A et l'Anèmie. Yaoundé (Cameroon): Ministère de la Santè Publique.

15. Engle-Stone, R., Haskell, M. J., Ongla Ndjebayi, A., Nankap, M., Erhardt, J. G., Gimou, M. M., Brown, K. (2011). Plasma Retinol-Binding Protein Predicts Plasma Retinol Concentration in Both Infected and Uninfected Cameroonian Women and Children. J. Nutr. 141, 2233-41.

16. Lin, L., Liu, Y., Ma, G., Tan, Z., Zhang, X., Jiang, J., Song, X., Wang, L., Zhang, J., Wang, H., Li, M. (2002). Survey on vitamin A deficiency in children under-6years in China (Article in Chinese). Zhonghua $\mathrm{Yu}$ Fang Yi Xue Za Zhi 36, 315-8.

17. Material for the Press Conference of the State Council Information Office. (2004). The Nutrition and Health Status of the Chinese People October 12, 2004. (Downloaded on January 16, 2014 from http:// www.goldenrice.org/PDFs/China_nutr_rep_2004_ en.pdf)

18. Tang, G., Gu, X., Hu, S., Xu, Q., Qin, J., Dolnikowski, G. G., Fjeld, C. R., Gao, X., Russell, R. M., Yin, S. (1999). Green and yellow vegetables can maintain body stores of vitamin A in Chinese children. Am. J. Clin. Nutr. 70, 1069-76.

19. Tang, G., Qin, J., Hao, L. Y., Yin, S. A., Russell, R. M (2002). Use of a short-term isotope-dilution method for determining the vitamin A status of children. Am. J. Clin. Nutr. 76, 413-8.

20. Wang, Z., Jiao, H., Cao, M., Tang, G., Zhao, X., Yin, S. (2003). Evaluation on intestinal and whole-body conversion of beta-carotene to vitamin A in Chinese adults using a stable isotope reference method (article in Chinese). Wei Sheng Yan Jiu. 32, 215-21.

21. Wang, Z., Yin, S., Zhao, X., Russell, R. M., Tang, G. (2004). beta-Carotene-vitamin A equivalence in Chinese adults assessed by an isotope dilution technique. Br. J. Nutr. 91, 121-31.

22. Tang, G., Hu, Y., Yin, S., Wang, Y., Dallal, G. E., Grusak, M. A., Russell, R. M. (2012). b-Carotene in Golden Rice is as good as b-carotene in oil at providing vitamin A to children. Am. J. Clin. Nutr. 96, 658-64.

23. Yu, Y., Zhao, Y., Pan, L., Yin, S. (2012). Advances on studies related to the requirement of vitamin A for infants, young and preschool children (Review in Chinese). Wei Sheng Yan Jiu. 41, 132-6.

24. Wang, Z., Li, Y., Du, Z., Shao, Z., Wu, J., Tang, G. (2013). Study on vitamin A requirement of adult Chinese by isotope dilution technique and intervention trial. Faseb J. 27, lb248 (abstract).

25. Zeng, J., Yao, P., Xu, J., Hao, L., Li, Z., Tang, G., Cao, W., Sun, X., Yang, X. (2012). Establishment of vitamin A requirement for Chinese children. Faseb J. 26, 118.6 (abstract).

26. Haskell, M. J., Jamil, K. M., Peerson, J. M., Wahed, M. A., Brown, K. H. (2011). The paired deuterated retinol dilution technique can be used to estimate the daily vitamin A intake required to maintain a targeted whole body vitamin A pool size in men. J. Nutr. 141, 428-32.

27. Valentine, A. R., Davis, C. R., Tanumihardjo, S. A. (2013). Vitamin A isotope dilution predicts liver stores in line with long-term vitamin A intake above the current Recommended Dietary Allowance for young adult women. Am. J. Clin. Nutr. 98, 1192-9.

28. Ministry of Finance and Economic Planning. (2012). Highlights of the 2012 budget, Republic of Ghana. (Downloaded on January 16, 2014 from http://www. mofep.gov.gh/sites/default/files/budget/2012_budget_ highlights.pdf)

29. Ghana Statistical Service (GSS), Ghana Health Service (GHS), and ICF Macro. (2009). Ghana Demographic and Health Survey 2008: Key Findings. Calverton, Maryland, USA: GSS, GHS, and ICF Macro. (Downloaded on January 16, 2014 from http:// www.measuredhs.com/pubs/pdf/SR172/SR172.pdf )

30. Takyi, E. E. K. (1999). Children's consumption of dark green, leafy vegetables with added fat enhances serum retinol. J. Nutr. 129, 1549-54.

31. Micronutrient Initiative. (2006). Controlling Vitamin \& Mineral Deficiencies in India-Meeting the Goal, New Delhi: Micronutrient Initiative. http://www. micronutrient.org/resources/publications/Controlling $\% 20$ VMD \%20India.pdf 
32. Maternal and child health scheme for prophylaxis against nutritional blindness in children caused by vitamin A deficiency. (1970). Family Planning Programme, Fourth Five-Year Plan Technical Information: MCH No. 2. New Delhi: Government of India Press; 1970. p. 1-22.

33. National Nutrition Monitoring Bureau. (2006). Prevalence of vitamin A deficiency among preschool children in rural areas. NNMB Technical Report No. 23. National Institute of Nutrition. Indian Council of Medical Research.

34. Sinha, A., Jonas, J. B., Kulkarni, M., Nangia, V. (2011). Vitamin A deficiency in schoolchildren in urban central India: the central India children eye study. Arch. Ophthalmol. 129, 1095-6.

35. Basu, S., Sengupta, B., Roy Paladhi, P.K. (2003). Single megadose vitamin A supplementation of Indian mothers and morbidity in breastfed young infants. Postgrad. Med. J. 79, 397-402.

36. Goyle, A., Prakash, S. (2011). Effect of supplementation of micronutrient fortified biscuits on serum total proteins and vitamin A levels of adolescent girls (10-16 years) of Jaipur city, India. Nepal Med. Coll. J. 13, 233-7.

37. Osei, A.K., Rosenberg, I.H., Houser, R.F., Bulusu, S., Mathews, S., Hamer, D.H. (2010). Communitylevel micronutrient fortification of school lunch meals improved vitamin $\mathrm{A}$, folate, and iron status of schoolchildren in Himalayan villages of India. J. Nutr. 140, 1146-54.

38. Varma, J.L., Das, S., Sankar, R., Venkatesh Mannar, M.G., Levinson, F.J., Hamer, D.H. (2007). Community-level micronutrient fortification of a food supplement in India: a controlled trial in preschool children aged 36-66 mo. Am. J. Clin. Nutr. 85, $1127-33$

39. Vinodkumar, M., Erhardt, J.G., Rajagopalan, S. (2009). Impact of a multiple-micronutrient fortified salt on the nutritional status and memory of schoolchildren. Int. J. Vitam. Nutr. Res. 79, 348-61.

40. Vinod Kumar, M., Nirmalan, P., Erhardt, J., Rahmathallah, L., Rajagopalan, S. (2014) An efficacy study on alleviating micronutrient deficiencies through a multiple micronutrient fortified salt in children in South India. Asia Pac J Clin Nutr. 23 (http://apjen.nhri.org.tw/server/APJCN/23/3/2484. pdf).

41. Kapil, U., Sachdev, H.P.S. (2013). Massive dose vitamin A programme in India - Need for a targeted approach. Indian. J. Med. Res. 138, 411-7.
42. UNICEF. (2009). The state of the world's children special edition. Celebrating 20 years of the convention on the rights of the child. Statistical tables. Downloaded from http://www.unicef.org/rightsite/ sowc/statistics.php.

43. Tanumihardjo, S. A., Permaesih, D., Dahro, A. M., Rustan, E., Muhilal, Karyadi, D., Olson, J. A. (1994). Comparison of vitamin A status assessment techniques in children from two Indonesian villages. Am. J. Clin. Nutr. 60, 136-41.

44. Tanumihardjo, S. A., Muherdiyantiningsih, Permaesih, D., Dahro, A. M., Muhilal, Karyadi, D., Olson, J. A. (1994). Assessment of the vitamin A status in lactating and nonlactating, nonpregnant Indonesian women by use of the modified-relativedose-response (MRDR) test. Am. J. Clin. Nutr. 60, $142-7$.

45. Rosmalina, Y., Permaesih, D., Fajarwati, T., Herman, S. (2009). The effects of distribution of vitamin A fortified cooking oil on vitamin a body reserve of breast feeding mothers (article in Indonesian Language). Penel. Gizi Makan. 32, 139-49.

46. Tanumihardjo, S.A., Olsen, J.A. (1991). The reproducibility of the modified relative dose response (MRDR) assay in healthy individuals over time and its comparison with conjunctival impression cytology (CIC). Eur. J. Clin. Nutr. 45, 407-11.

47. Rivera, J., Shamah, T., Villalpando, S., González de Cossio, T., Hernández B., Sepúlveda, J. (2001). National nutrition survey in children and women in Mexico 1999 (text in Spanish). Instituto Nacional de Salud Pública.

48. Robles, A., Astiazaran, H., Dávalos, N., Quihui, L., Cabrera, P., Valencia, M. (1998). Effect of massive vitamin A supplement in children from 6 to 36 months of age (article in Spanish). Sal. Pub. Mex. 40, 309-15.

49. Astiazaran-Garc'a, H., Lopez-Teros, V., Valencia, M., Vázquez-Ortiz, F., Sotelo-Cruz, N., Quihui-Cota, L. (2010). Giardia lamblia infection and its implications for vitamin A liver stores in school children. Ann. Nutr. Metab. 57, 228-33.

50. Gonzalez, D. (2005). Effect of cooked school breakfast intake on micronutrients nutritional status and body composition in Sonoran children (text in Spanish). Hermosillo, Mexico, Centro de investigación en alimentación y desarrollo, A. C.

51. Villalpando, S., Shamah, T., Garc'a, A., Mundo, V., Dom'nguez, C., Mej'a, F. (2009). The prevalence of anemia decreased in Mexican preschool and schoolage children from 1999 to 2006. Sal. Pub. Mex. 51, S507-14. 
52. Lopez-Teros, V., Quihui, L., Gutiérrez-Rivera, M., Duarte-Figueroa, M., Esparza-Romero, J., Pacheco, B., Tortoledo, O., Rascón-Durán, L., AstiazaranGarc'a, H. (2012). Food components and dietary habits and its association with anthropometric indices in preschoolers from Hermosillo, Sonora (text in Spanish). Biotecnia 14, 44-53.

53. Furr, H. C, Amedee-Manesme, O., Clifford, A. J., Bergen, H. III, Jones, A. D., Anderson, D. P., Olson, J. A. (1989). Vitamin A concentration in liver determined by isotope dilution assay with tetradeuterated vitamin A and by biopsy in generally healthy adult humans. Am. J. Clin. Nutr. 49, 713-6.

54. Lopez-Teros, V., Quihui-Cota, L., Méndez-Estrada, R. O, Grijalva-Haro, M. I., Esparza-Romero, J., Valencia, M. E., Green, M. H., Tang, G., PachecoMoreno, B. I., Tortoledo-Ortiz, O., AstiazaranGarcia, H. (2013). Vitamin A fortified milk increases total body vitamin A stores in Mexican preschoolers. J. Nutr. 143, 221-6.

55. Idohou-Dossou, N., Diouf, A., Ba-Lo, N., Ndour, D., Faye, MH., Guiro, A T., Sall, M G., Ndiaye, B., Wade, S. (2013). Concurrent deficiencies of iron, zinc and vitamin A in Senegalese women aged 15-49 years: a national study. Ann. Nutr. Metab. 63,822 (abstract).

56. Diouf, A. Idohou-Dossou, N., Ba-Lo, N., Sy, M., Diatta, AD., Fall Beye, M., Manga, LD., Guiro, AT., Sall, MG., Ndiaye, B., Wade, S. (2013). Concurrent deficiencies of iron, zinc and vitamin A in Senegalese infants aged 12-59 months: a national study. Ann. Nutr. Metab. 63,822 (abstract).

57. Agne-Djigo, A., Idohou-Dossou, N., Kwadjode, K. M., Tanumihardjo, S. A., Wade, S. (2012). High prevalence of vitamin A deficiency is detected by the modified relative dose-response test in six-month-old Senegalese breast-fed infants. J. Nutr. 142, 1991-6.

58. Wasantwisut, E., Chittchang, U., Sinawat, S. (2000). Moving a health system from a medical towards a dietary approach in Thailand. Food Nutr. Bull. 21,157-60.

59. Pinkaew, S., Wegmuller, R., Wasantwisut, E., Winichagoon, P., Hurrell, R. F., Tanumihardjo, S. A. (2014). Triple-fortified rice containing vitamin A reduced marginal vitamin A deficiency and increased vitamin A liver stores in school-aged Thai children. J. Nutr. 144, 1-6.

60. Hautvast, J. L., Tolboom, J. J., West, C. E., Kafwembe, E. M., Sauerwein, R. W., van Staveren, W. A. (1998). Malaria is associated with reduced serum retinol levels in rural Zambian children. Int. J. Vitam. Nutr. Res. 68, 384-8.
61. Christian, P., Schulze, K., Stoltzfus, R.J., West, K.P., Jr. (1998) Hyporetinolemia, illness symptoms, and acute phase protein response in pregnant women with and without night blindness. Am. J. Clin. Nut. 67, 1237-43.

62. Filteau, S.M., Morris, S.S., Raynes, J.G., Arthur, P., Ross, D.A., Kirkwood, B.R., Tomkins, A.M., Gyapong, J.O. (1995) Vitamin A supplementation, morbidity, and serum acute-phase proteins in young Ghanaian children. The American journal of clinical nutrition $62,434-8$.

63. Rosales, F.J., Ritter, S.J., Zolfaghari, R., Smith, J.E., Ross, A.C. (1996) Effects of acute inflammation on plasma retinol, retinol-binding protein, and its mRNA in the liver and kidneys of vitamin A-sufficient rats. Journal of lipid research 37, 962-71.

64. National Food and Nutrition Commission. (2003). Report of the National Survey to Evaluate the Impact of Vitamin A Interventions in Zambia in July and November 2003. Lusaka, Zambia.

65. Bresnahan, K.A., Chileshe, J., Arscott, S., Nuss, E., Surles, R., Masi, C., Kafwembe, E., Tanumihardjo, S.A. (2014). The acute phase response affected traditional measures of micronutrient status in rural Zambian children during a randomized, controlled feeding trial. J. Nutr. 144, 972-8.

66. Tang, G., Qin, J., Dolnikowski, G.G. (1998). Deuterium enrichment of retinol in humans determined by gas chromatography electron capture negativechemical ionization mass spectrometry. J. Nutr. Biochem. 9, 408-14.

67. Tanumihardjo, S.A. (2000). Vitamin A Status Assessment in Rats with ${ }^{13} \mathrm{C}_{4}$-Retinyl Acetate and Gas Chromatography/Combustion/Isotope Ratio Mass Spectrometry. J. Nutr. 130, 2844-9.

68. Oxley, A., Berry, P., Taylor, G.A., Cowell, J., Hall, M.J., Hesketh, J., Lietz, G., Boddy, A.V. (2014). An $\mathrm{LC} / \mathrm{MS} / \mathrm{MS}$ method for stable isotope dilution studies of $\beta$-carotene bioavailability, bioconversion, and vitamin A status in humans. J. Lipid. Res. 55, 319-28.

\section{Veronica Lopez-Teros}

Nutritional Sciences, Department of Biological and Chemical Sciences

Universidad de Sonora

Hermosillo

Mexico

veronica.lopez@guayacan.uson.mx 